\title{
Mindfulness Training Gets an Upgrade: Innovations in Mental and Emotional Self-Management (MESM) to Combat Stress in Organizations
}

\author{
Rhonda K. Rodgers \\ Claremont Graduate University \\ Vanessa L. Kettering \\ Claremont Graduate University
}

Neuroscientists suggest that chronic stress diminishes cognitive ability, therefore rendering metacognitive exercises such as mindfulness training ineffective for many. An intervention was tested that incorporates tools to regulate the stress response prior to engaging metacognitive stress management techniques. A mixed-method study $(N=147)$ compared business students with Amazon's mechanical Turkers. After three weeks of practice, trainees scored higher in mindful attention and well-being and training explained $16 \%$ of test score variance, suggesting a moderate to large effect size. This pilot study exposes a potential shortcoming in current forms of organizational mindfulness training and offers a solution for future intervention design.

\section{INTRODUCTION}

Organizational researchers estimate more than 120,000 deaths per year and approximately five to eight percent of healthcare costs are attributable to work-related stress in the United States (Goh, Pfeffer, $\&$ Zenios, 2015). The impact of stress can also influence workplace metrics such as absenteeism, presenteeism, compensation claims, and productivity (Siegrist, 2001). Beyond the workplace, stress is now an epidemic in the U.S., as are the social and financial implications of stress related lifestyle and disease (American Psychological Association, 2014). It is more feasible to develop resiliency to stress rather than eradicate the spectrum of personal and work-related stressors, and mindfulness training has become a popular intervention to address the needs of an increasingly overburdened workforce.

Mindfulness training as a person-level organizational intervention has been successful in efforts to reduce burnout (Langer, Heffernan, \& Kiester, 1988) and decrease organizational accidents (Weick, Sutcliffe, \& Obstfeld, 1999). However, an equally salient challenge to organizations is the growing number of workers subjected to chronic stressors (e.g., threat to job security, long work hours) and traumatic events (e.g., military deployment, natural disaster, and micro aggressions against marginalized populations such as minorities and women). The World Health Organization reports that traumatic events are commonplace around the world, and in a study of 21 countries, $22 \%$ of respondents reported witnessing violence, $16 \%$ reported exposure to war, and $4 \%$ reported symptoms of post-traumatic stress disorder (World Health Organization, 2013). 
In organizational literature, mindfulness is regarded as a cognitive practice to develop attention to current experiences (Weick \& Putnam, 2006), leading to behavior regulation (Brown \& Ryan, 2003). Organizations ranging from Google to Harvard Business School have implemented mindfulness training (MT) as a means to increase awareness of how the mind and emotions can affect perception and decisionmaking (e.g., Gardiner, 2012; Gelles, 2012). In this context, MT is designed to develop skills in metacognitive awareness, or the ability to pay attention to what one is thinking about and to notice the strategies one employs while thinking (e.g., Segal, Teasdale, \& Williams, 2004). However neuroscience studies suggest that humans have difficulty sustaining attention or accessing complex thought processes while experiencing chronic stress (e.g., Arnsten, 1998; Sapolsky, 2004). Which leads to the conclusion that organizational mindfulness training may be inappropriate for the chronically stressed populations it is intended to serve.

During non-stressful situations, the complex associative cortex of the brain contributes to reasoned decision-making, however during emotionally charged or unexpected situations, the more primitive areas of the brain (e.g., amygdalar complex and hippocampus) become activated (e.g., Porges, 2004). In such cases, cognitive or "thought based" processes are offline and can only be accessed after the nervous system is brought back into its natural state of balance (Goleman, 1996; LeDoux, 1994).

\section{Chronic Stress and Nervous System Regulation}

Stressful events may be fleeting in nature for some individuals, but for others such as those experiencing chronic (i.e., prolonged) or traumatic (i.e., extreme) stress, the autonomic nervous system can become stuck in fight or flight or freeze rather than returning to a resting baseline (e.g., Cannon, 1915; Korte, Koolhaas, Wingfield, \& McEwen, 2005). Through repeated exposure to stress, even a small stressor can bump an individual out of their window of tolerance (Siegel, 2010). In the workplace these individuals may be known as employees with a "short fuse", however this is a normal biological reaction for someone suffering from chronic or traumatic stress. When stress occurs, physiological processes engage the brain, body, and nervous system to respond. Many humans naturally return to equilibrium after a stressful event, however many need assistance (Siegel, 2011).

The objective is therefore to engage the natural biology of the human organism to return to a state of balance known as the "resilient zone" or condition of mind-body where humans can navigate the challenges of daily life (Miller-Karas, 2015). Different individuals require varying levels of treatment, and in certain circumstances a trained professional may not be available. The Trauma Resource Institute has developed two programs to meet these needs: The Trauma Resiliency Model and the Community Resiliency Model.

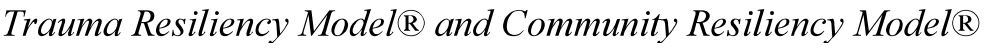

The Trauma Resiliency Model ${ }^{\circledR}$ (TRM) is a biologically based treatment that assists clients exposed to stressful and traumatic events stabilize their nervous system. The goal is to help clients discern the differences between sensations of distress and well-being and to help the body release distressing sensations and return to equilibrium. Therapy is accomplished with a TRM certified practitioner who is licensed in a mental health specialty or being supervised for licensure. The Community Resiliency Model (CRM) is a condensed version of TRM that can be taught peer to peer, in a culturally sensitive way, without the aid of a clinician.

Community Resiliency Model skills have been taught to numerous vulnerable populations, including survivors of natural disaster, veterans of war, and marginalized communities (e.g., Citron \& Miller-Karas, 2013; Leitch, Vanslyke, \& Allen, 2009). Two aspects of this model are particularly well suited to the organizational domain. First, the short-format model was created for dissemination to those who do not have time or funding to receive longer-term treatment, and second, the biological stabilization skills are suitable for those who do not have a background in mental health. The U.S. Department of Defense named TRM a promising practice for treating stress in U.S. service members (Moore, Brown, Money, \& Bates, 2011), and CRM expands this possibility for civilian organizations. Through CRM training participants learn to bring attention to sensations in the body and then learn self-directed techniques to 
deal with these biological reactions to stress. Participants are taught that stress is a natural biological response to extraordinary circumstances, and are instructed in skills to return their autonomic nervous system back into the resilient zone (see Figure 1) where healing can occur (Miller-Karas, 2015).

\section{FIGURE 1 \\ THE AUTONOMIC NERVOUS SYSTEM AND RESILIENT ZONE}

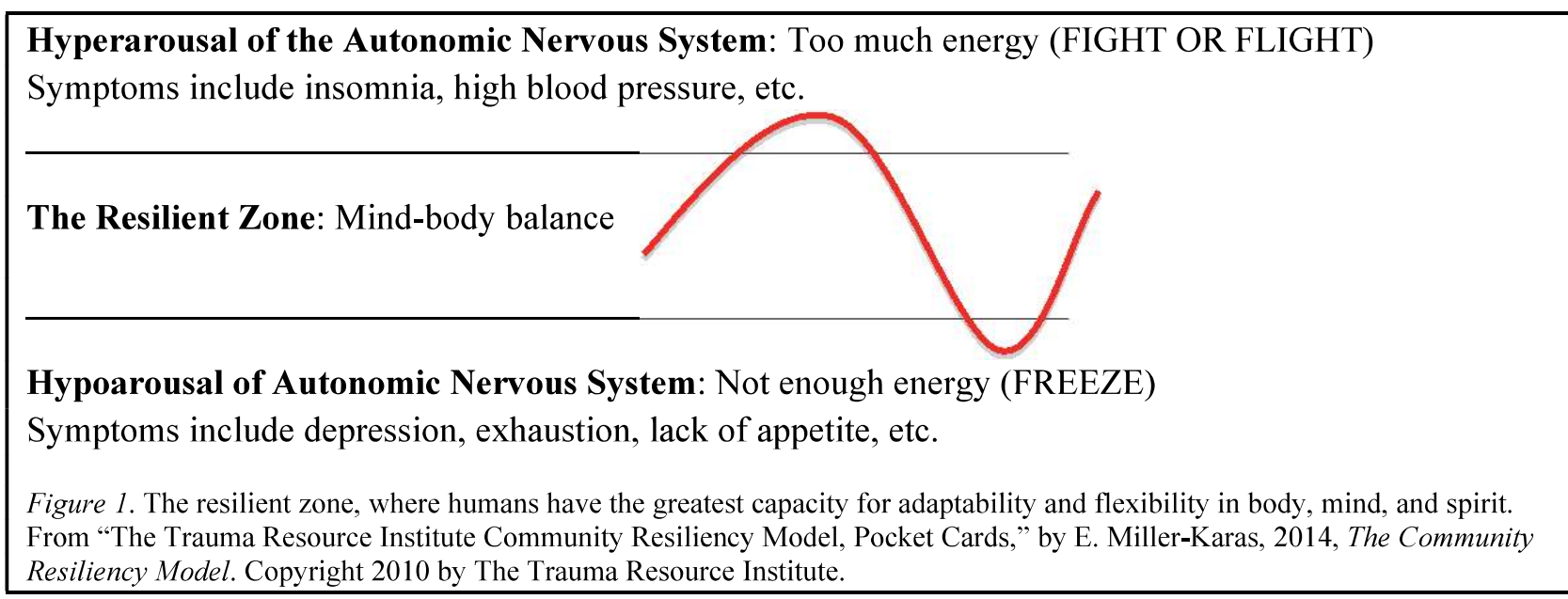

\section{Building an Effective Organizational Stress Intervention}

Chronic stress is a growing challenge for organizations and mind centered techniques such as MT may not present a viable intervention for this population. Mindfulness Based Stress Reduction (MBSR; Kabat-Zinn, Lipworth, \& Burney, 1985), addresses the mind, body, and nervous system, and has been shown to reduce chronic stress symptoms in both clinical and healthy populations (e.g., Chiesa \& Serretti, 2009; Matousek, Dobkin, \& Pruessner, 2010). Ideally, this would be the go-to intervention for the organizational world, however the eight-week MBSR format has not been widely adopted by non-clinical organizations.

To address these issues, the elements of a business school course in self-management were combined with a biologically based technique for nervous system regulation (CRM), into a two-hour classroom intervention in Mental and Emotional Self-Management (MESM), followed by three weeks of home practice. This mixed method study explores the efficacy of MESM as a stress intervention that can be applied both at home and in the workplace. A convergent parallel design was used in which both quantitative and qualitative data were collected, analyzed, and the results were compared to explain convergent outcomes.

The aims of the pilot study are to provide proof of concept that MESM training produces well-being outcomes comparable to those found in organizational MT studies, and to qualitatively elucidate trainee experiences for improving future MESM intervention design.

H1-MESM trainees will have higher post-test levels of attentional control (mental self-management) than the control group.

H2-MESM trainees will have higher post-test levels of well-being (emotional self-management) than the control group.

\section{METHOD}

A between-subjects design was utilized to measure changes in mindful attention, and positive and negative affect, after a three-week MESM intervention. The experiment and comparison groups were comprised of undergraduate business students. Whereas participants in the control group were recruited online through the crowd-sourcing website, mechanical Turk (mTurk) by Amazon. This group received 
neither training nor direction for home practice, but were given the same pre and post-test measures, administered online, with a three-week duration between surveys.

Participants in both experiment and comparison groups received two hours of MESM training, and surveys were adminstered prior to classroom training at week one and again at week three.

In addition, participants in the experiment group were asked to meditate 45 minutes per week (i.e. three days per week, 15 minutes per day), to determine if the home meditation practice had an additive well-being effect.

\section{Design}

Following quasi-experimental design, participants were randomized by classroom and students in each condition were given training as a complete class. Mixed method research is appropriate when quantitative or qualitative studies independently are insufficient to fully understand the depth of the study (Creswell, 2013). Therefore, a mixed method design was utilized with the rationale and purpose of complementarity; the results from the qualitative analysis were interpreted to enhance, expand, and clarify findings from the quantitative study (Greene, Caracelli, \& Graham, 1989). The chronological steps of the convergent parallel design are presented in Figure 2.

\section{FIGURE 2}

\section{MIXED METHODS RESEARCH: CONVERGENT PARALLEL DESIGN}

\begin{tabular}{|l|}
\hline Quantitative Data Collection \& Analysis $\rightarrow$ Results $\rightarrow$ Compare Results $\rightarrow$ Interpret \\
Qualitative Data Collection \& Analysis $\rightarrow$ Results \\
Figure 2. In parallel data analysis, the two different analyses are compared or consolidated after the full analyses \\
(Octlund, Kidd, Wengstrom, \& Rowa-Dewar, 2011).
\end{tabular}

Two modes of qualitative data were collected: weekly written journals and one-time recorded interviews. Trainee experience journals were guided by a structured questionnaire asking participants to describe stressful moments, calming moments, and their overall reactions to training during the threeweek intervention (see Appendix A). At week three, trainees were invited to share their experiences during the study through digitally recorded interviews. A semi-structured format was used to allow flexibility for each respondent to add to the discussion at will. The interview guide consisted of two banks of questions with additional probes (see Appendix B) to query participants about their overall experiences during training, and to explore participants' interpretations of the core principles of training in "meditation" and "self-management". Syntheses of both quantitative and qualitative findings are presented in the results section below.

\section{Participants}

Participants in the experiment group $(n=85)$ and comparison group $(n=20)$ were business students in Southern California. The demographics for the experiment group were $\left(n=62, M_{\text {age }}=24.2\right.$ years; range: $18-52 ; 52 \%$ female), and comparison group ( $n=16, M_{\text {age }}=24.7$ years; range: $20-36 ; 44 \%$ female). Individuals in the control group $(n=200)$ were recruited from Amazon's Mechanical Turk. Participants were remunerated for their time spent taking the two online surveys (40 cents for pre-test and 30 cents for post-test), and 69 participants (35\% of the initial sample) completed the post-test $\left(n=69 ; M_{\text {age }}=36.7\right.$ years; range: $21-64 ; 52 \%$ female). 


\section{Measures}

For the quantitative portion of the study, two instruments were chosen: The Mindful Attention Awareness Scale (MAAS; Brown \& Ryan, 2003) and the Scale of Positive and Negative Affect (SPANE; Diener et al., 2009). These instruments are common in organizational MT studies, and were chosen for their efficacy in detecting changes after a short training dosage. Quantiative measures were purposefully limited to two instruments to lessen respondent fatigue.

\section{Mindful Attention Awareness Scale}

The fifteen-item MAAS is scored on a six point Likert scale from 1 (almost always) to 6 (almost never) and includes items such as "I find it difficult to stay focused on what's happening in the present" and "I snack without being aware that I'm eating" (Brown \& Ryan, 2003). The scale is arranged such that higher item scores represent lower levels of distractibility and thus greater levels of awareness and attention. The trait MAAS has shown excellent psychometric properties across multiple studies with alpha values generally ranging from .80 to .90 (e.g., Brown \& Ryan, 2003; MacKillop \& Anderson, 2007). Cronbach's alpha in the present study was .91, and participants' scores were obtained by calculating mean averages for items in the scale.

\section{Scale of Positive and Negative Experience}

The twelve-item SPANE is used to measure duration of positive and negative feelings and experiences over a specific period of time in one's life, which is indicative of levels of general well-being (Diener et al., 2009). The scale is scored on a five point Likert scale from 1 (very often or always) to 5 (very rarely or never) and includes the following instructions: "think about what you have been doing or experiencing for the past three weeks; then report how much you experienced each of the following feelings on the scale below." The feelings listed are "positive, negative, good, bad, pleasant, unpleasant, happy, sad, afraid, joyful, angry, and contented" (Diener et al., 2009). The SPANE was separated into two scales, one measuring positive experiences (SPANE P), and one measuring negative experiences (SPANE $\mathrm{N})$. Items in the SPANE $\mathrm{N}$ are arranged such that higher item scores represent lower levels of negative experiences and items in the SPANE P are reverse scored, such that higher item scores represent lower levels of positive experiences. This subscale was reverse coded during the analysis phase of the study to match the direction of the other variables such that higher scores indicate higher levels of well-being. Cronbach's alpha in the present study for the SPANE P was .94 and the SPANE N was .92. Scores for both the positive and negative experience scales were calculated by summing the total number of items endorsed on each factor.

In addition to these quantitative measures, documents and interviews were utilized as complementary qualitative modalities of data collection.

\section{Experimental Intervention}

The Mental and Emotional Self-Management (MESM) intervention consists of a two-hour classroom session designed to impart tactical skills in biological nervous system regulation, based upon the Community Resiliency Model (CRM; Leitch \& Miller-Karas, 2010), and strategic skills for stress management based upon the principles of behavior modification and social learning theory (Bandura, 1969/1971). The first phase of training teaches skills to balance the nervous system during stressful life scenarios.

\section{Tactical Tools}

The autonomic nervous system (ANS) is part of the human biological defense mechanism. During threatening situation, the ANS may trigger the sympathetic nervous system into fight or flight or the parasympathetic nervous system into freeze. The Community Resiliency Model (CRM; Leitch \& MillerKaras, 2010) is a biology-based set of six skills, which help participants to reset their nervous systems after a challenging experience. The first three skills of CRM: Resourcing, Grounding, and Tracking were taught to participants as a tool kit to use whenever a heat of the moment stressor appeared (e.g., an 
encounter with an aggressive driver during the morning commute, a challenging interaction with a boss or coworker). The iChill mobile application, which contains instruction in all six CRM skills, was also suggested as a resource (Trauma Resource Institute, 2014). However participants were not required to download or practice these skills. A summary of the various skills incorporated into MESM training and comparison with other modalities of stress management are illustrated in Table 1.

\section{TABLE 1 STRESS INTERVENTION PROGRAM ELEMENTS}

\begin{tabular}{lllll}
\hline Intervention & $\begin{array}{l}\text { Metacognitive } \\
\text { Training }\end{array}$ & $\begin{array}{l}\text { Nervous System } \\
\text { Regulation }\end{array}$ & Meditation & Yoga \\
\hline MESM & Yes & Yes & Yes & No \\
MBSR & Yes & Yes & Yes & Yes \\
CRM & Yes & Yes & No & No \\
MT & Unclear & Unclear & Unclear & Unclear \\
\hline
\end{tabular}

Note. MESM: Mental and Emotional Self-Management, MBSR: Mindfulness Based Stress Reduction (Kabat-Zinn, Lipworth, \& Burney, 1985), CRM: Community Resiliency Model (Leitch \& Miller-Karas, 2010), MT: Mindfulness Training, is currently not a standardized training platform and therefore different programs contain different elements (e.g., Good et al., 2015).

\section{Strategic Tools}

Hunter and Drucker (2009) describe the practice of self-management as a process by which a worker can look within their inner "black box" to illuminate internal processing and enhance personal effectiveness. To do so, the individual must first become aware of such inner processes and then understand how they can be regulated.

Trainees were first introduced to concepts relating to metacognition or the ability to give attention to one's thought patterns, as well as information on common biases that limit flexibility in metacognition, along with adaptations for these biases including: the control of psychic energy (Csikszentmihalyi, 1990), positivity (Fredrickson, 2009), mindset (Dweck, 2008), learning orientation (Adams, 2009), and the workings of the adaptive unconscious (Wilson, 2002).

Empirical studies that illustrate the physiological influence of meditation were also shared with participants. These studies highlighted the effects of meditation on brain functions, such as attentional control, cognitive style, and affect (e.g., Chambers, Lo, \& Allen, 2008; Hasenkamp, Wilson-Mendenhall, Duncan, \& Barsalou, 2012), alteration of emotion related structures in the brain (e.g., Hölzel et al., 2011), and immune system support (Ospina et al., 2007). Trainees were also introduced to exemplars in the field of meditation such as successful athletes and businesspeople that credit their mental clarity to meditation practice. Trainees were then given instruction in basic breath counting meditation, and the experiment group was given access to an online guided "building attention" meditation (Hunter, 2013) for home practice.

Next, trainees were given an introduction to the evolutionary biology of the brain and stress in humans (Sapolsky, 2004), as well as an introduction to the behavioral neuroscience of amygdala response to stressors and sub-conscious reactivity (LeDoux, 1994). Finally, it was emphasized that cognitive components of learning and metacognition (i.e., thinking about one's thought processes) are better suited for low stress situations and that both strategic and tactical tools were to be practiced for maximum benefit. 


\section{RESULTS}

The researchers utilized a quantitative dominant mixed analysis, wherein quantitative analysis was prioritized and qualitative analysis was used to increase understanding of quantitative results.

\section{Quantitative Analysis}

Correlation tables were analyzed for demographics including gender, age, race, occupation, and managerial status, across the three groups at time one. Significant relationships were found between training condition and demographic variables including occupation, age, and race (see Table 2), and these factors were controlled for in subsequent analyses.

\section{TABLE 2 \\ CORRELATIONAL MATRIX FOR TRAINING CONDITIONS AND DEMOGRAPHICS AT TIME ONE}

\begin{tabular}{|c|c|c|c|c|c|c|c|c|}
\hline Variable & IV Group & Occupation & Gender & Age & Manager & Attention & Positive & Negative \\
\hline IV Group & - & & & & & & & \\
\hline Occupation & $-.30 * *$ & & & & & & & \\
\hline Gender & .01 & 0 & & & & & & \\
\hline Age & $.55^{* *}$ & $-.35 * *$ & .02 & & & & & \\
\hline Manager? & .08 & $.18 *$ & .11 & -.1 & & & & \\
\hline Race_White & $.57 * *$ & $-.40 * *$ & -.09 & $.49 * *$ & -.06 & $.22 * *$ & 0 & .15 \\
\hline Race_Black & -.04 & -.13 & .19 & $-.03 * *$ & .07 & .09 & -.09 & -.06 \\
\hline Race_Asian & $-.18^{*}$ & $-.54 * *$ & -.03 & -.32 & .09 & $-.17 *$ & -.1 & $-.18 *$ \\
\hline Race_Latino & $-.40 * *$ & .03 & .04 & -.19 & -.01 & -.03 & .14 & .06 \\
\hline Race_Mix & -.11 & .03 & .92 & -.08 & .09 & -.13 & 0 & -.03 \\
\hline Race_MiddleEast & -.16 & .07 & -.01 & $-.14 * *$ & .03 & -.14 & .03 & -.06 \\
\hline Attention & $.33^{* *}$ & $-.23 * *$ & -.03 & $.33 * *$ & -.11 & - & $.33^{* *}$ & $.48 * *$ \\
\hline Positive & -.14 & -.12 & .15 & -.1 & -.12 & $.33^{* *}$ & - & $.66^{* *}$ \\
\hline Negative & .12 & $-.23 * *$ & 0 & .13 & -.06 & $.48^{* *}$ & $.66^{* *}$ & - \\
\hline
\end{tabular}

Note. IV group represents the two training groups (experiment and control) in aggregate. Occupation represents either full-time student or at least part-time employee. Manager represents whether the participant supervises others. Correlations for time one measures include the Mindful Attention Awareness Scale which measures attentional control (labeled attention), Scale of Positive and Negative Experiences- Positive which measures positive emotions and experiences in the past three weeks (labeled positive), and Negative which measures negative emotions and experiences in the past three weeks (labeled negative). ${ }^{*} p<.05 .{ }^{* *} p<.01$.

A two-tailed chi-square test of independence was conducted between demographic variables and the three groups of participants; a statistically significant association between age and training groups $(p<$ .05 ; FET) was found. Post hoc tests revealed that young adults (ages18-33 years) were overrepresented in the experiment group and underrepresented in the control group, whereas middle adults (ages 34-49 years) were underrepresented in the experiment group and overrepresented in the control group. To control for potential confounds, the time one scores on the three scales, and demographic variables including gender, age, race, occupation, and managerial status were entered as covariates during time two analyses.

First, pre-test scores were analyzed on the three scales across the three conditions. The only significant effect observed in the data was for the scale measuring mindful attention (MAAS), $F(2,135)=$ $4.27, p<.05$. The control group scored higher on the MAAS $(M=4.32, S D=0.83)$ compared to the 
experiment group $(M=3.72, S D=0.83)$, suggesting that mTurkers had greater levels of mindful attention at time one. The pre-test scores for the three scales are presented in Table 3.

\section{PRE-TEST SCORE COMPARISON BETWEEN TRAINING GROUPS}

\begin{tabular}{|c|c|c|c|c|c|c|c|c|}
\hline \multirow[b]{2}{*}{ Scale } & \multirow[b]{2}{*}{$F(2)$} & \multirow[b]{2}{*}{$p$} & \multicolumn{2}{|c|}{$\begin{array}{l}\text { Experiment } \\
(\mathrm{n}=62)\end{array}$} & \multicolumn{2}{|c|}{$\begin{array}{c}\text { Comparison } \\
(\mathrm{n}=16)\end{array}$} & \multicolumn{2}{|c|}{$\begin{array}{c}\text { Control } \\
(\mathrm{n}=69)\end{array}$} \\
\hline & & & $M$ & $S D$ & $M$ & $S D$ & $M$ & $S D$ \\
\hline MAAS & 4.27 & 0.02 & 3.72 & 0.83 & 3.48 & 0.8 & 4.32 & 0.83 \\
\hline SPANE P & 0.61 & 0.55 & 21.56 & 4.06 & 21.1 & 4.36 & 20.3 & 5.09 \\
\hline SPANE N & 0.15 & 0.86 & 19.92 & 4.91 & 20.3 & 4.00 & 21.1 & 5.14 \\
\hline
\end{tabular}

Note. MAAS: Mindful Attention Awareness Scale (Brown \& Ryan, 2003), SPANE: Scale of Positive and Negative Experiences (Diener et al., 2009). SPANE P measures positive emotions and experiences while the SPANE N measures negative emotions and experiences. Higher scores (boldface) indicate higher levels of well-being.

Next, the post-test data were analyzed. Dependent variables consisted of the three scales mentioned above (MAAS, SPANE P, and SPANE N) collected at time two (T2). To control for pre-test differences across the three conditions the scales collected pre-test (T1) were specified as covariates as were demographic variables including: gender, age, race, occupation, and managerial status. A multivariate analysis of covariance (MANCOVA) via Statistical Package for the Social Sciences (SPSS) was performed using $\mathrm{T} 2$ data to test for training group differences in the multivariate composite of related dependent variables. The MANCOVA revealed a significant multivariate main effect for training condition, Pillai's Trace $=.16, F(6,262)=3.86, p<.01$, which explains approximately $16 \%$ of the variance in the DV set of measures, suggesting a moderate to large effect size (Cohen, 1988; Miles \& Shevlin, 2001).

To explore these significant omnibus results in training condition, univariate ANCOVAs were run on the individual scales. The test of between-subjects effects suggests a significant main effect for training condition in mindful attention (MAAS), $F(2,132)=5.55, p<.01$, positive experiences (SPANE P), $F(2$, $132)=7.68, p<.01$, and negative experiences (SPANE N), $F(2,132)=4.24, p<.05$, suggesting that training significantly influenced participant scores in attentional control and well-being.

Post hoc comparisons using Fisher's Least Significant Difference test revealed that participants in the experiment group differed significantly from participants in the control group on all three dependent variables, but participants in the comparison group did not differ significantly from the other groups, due to a lack of statistical power $(n=16)$.

After controlling for demographic variables and pre-test MAAS scores, the estimated marginal means for the experiment group were higher $(E M M=4.31, S E M=0.09)$ than the control group $(E M M=3.89$, $S E M=0.09)$. After controlling for demographic variables and pre-test SPANE scores, the experiment group had higher post-test scores $(E M M=23.51, S E M=0.47)$ for the positive experience scale than the control group $(E M M=20.49, S E M=0.47)$, and higher post-test scores for the negative experience scale $(E M M=22.35, S E M=0.55)$ than the control group $(E M M=19.86, S E M=0.56)$. Therefore, MESM trainees had significantly higher post-test levels of positive experiences and lower levels of negative experiences than the control group (see Table 4). 
TABLE 4

POST-TEST SCORE COMPARISON BETWEEN TRAINING GROUPS

\begin{tabular}{|c|c|c|c|c|c|c|c|c|c|c|c|c|c|c|}
\hline \multirow[b]{4}{*}{ Scale } & \multirow[b]{4}{*}{$F(2)$} & \multirow[b]{4}{*}{$p$} & \multicolumn{6}{|c|}{ Experiment $(n=62)$} & \multicolumn{6}{|c|}{ Control (n = 69) } \\
\hline & & & \multirow{2}{*}{\multicolumn{2}{|c|}{ Unadjusted }} & \multicolumn{4}{|c|}{ Adjusted } & \multirow{2}{*}{\multicolumn{2}{|c|}{ Unadjusted }} & \multicolumn{4}{|c|}{ Adjusted } \\
\hline & & & & & & & & ${ }_{0} \mathrm{CI}$ & & & & & & ${ }_{0} \mathrm{CI}$ \\
\hline & & & $M$ & $S D$ & $M$ & S.E. & $L L$ & $U L$ & $M$ & $S D$ & $M$ & S.E. & $L L$ & $U L$ \\
\hline MAAS & 5.6 & 0.01 & 4.04 & 0.72 & 4.31 & 0.1 & 4.14 & 4.48 & 4.23 & 0.89 & 3.89 & 0.09 & 3.72 & 4.06 \\
\hline SPANE P & 7.7 & 0.01 & 23.8 & 3.17 & 23.5 & 0.5 & 22.6 & 24.44 & 20.2 & 4.72 & 20.5 & 0.47 & 19.6 & 21.43 \\
\hline SPANE N & 4.2 & 0.02 & 21.4 & 4.58 & 22.4 & 0.6 & 21.3 & 23.45 & 21.0 & 5.03 & 19.9 & 0.56 & 18.8 & 20.96 \\
\hline
\end{tabular}

Note. $\mathrm{CI}=$ confidence interval; $\mathrm{LL}=$ lower limit; $\mathrm{UL}=$ upper limit. MAAS: Mindful Attention Awareness Scale (Brown \& Ryan, 2003), SPANE: Scale of Positive and Negative Experiences (Diener et al., 2009). SPANE P measures positive emotions and experiences while the SPANE N measures negative emotions and experiences. Unadjusted scores do not account for covariates. Adjusted scores account for age, gender, race, manager status, and occupation. Higher scores (boldface) indicate higher levels of well-being.

\section{Qualitative Analysis}

The researchers assumed a post positivist stance and sought objectivity through triangulating both quantitative and qualitative analyses. Content analysis is useful to gain knowledge and understanding of the phenomenon under study (Downe-Wamboldt, 1992), and so this approach was chosen to better understand participants' experiences during MESM training.

Conventional content analysis adheres to a naturalistic paradigm and is preferable when limited theory or research literature exists on a particular phenomenon (Hsieh \& Shannon, 2005), which is in line with the purpose of this study, to develop the concept of MESM as a training platform rather than propose a new line of theory (Lindkvist, 1981).

Document analysis was limited to complete sets of journals, and only ten participants submitted journals over the entire three-week period (see Appendix A for journal instructions and Appendix D for the document codebook). The weekly experience journals provided a greater understanding of how MESM training influenced participants' lives at home and work. However, a pattern emerged: students were using their own techniques as proxies for meditation and self-management. This prompted a need for further exploration, and a request for interview was sent to both training groups at week two. A total of nine students volunteered to be interviewed at the end of training (see Appendix B for the protocol and Appendix C for the codebook).

The two researchers each analyzed three journal entries and three interview transcripts. General themes were agreed upon and each researcher coded their data based upon these categories. The researchers then swapped documents and coded the other's data, and discrepant coding was discussed until consensus was reached on each code. In this phase of data reduction, constant comparison analysis (Glaser \& Strauss, 1967) was utilized to distill ten initial categories into two major themes: barriers to training and boosts to training, which included the use of substitute methods combined with MESM skills (see Appendices C and D for codebooks). These themes were transformed into dichotomous variables and an inter-respondent matrix (Onwuegbuzie, 2003) was used to calculate the frequency of each theme. The goal of qualitative analysis was to gain insight into the personal experiences of trainees and to use this phenomenological perspective to better understand the quantitative outcomes of this study.

The first theme of "barriers" pertained to those who attempted to use the tactical or strategic tools of MESM, but found challenges in executing these practices. For example, trainees reported a host of barriers to the guided meditation practice including: difficulty finding a time, place, and motivation to meditate. The second theme, "boosts" consisted of experiences that encouraged repeated MESM behaviors, which are critical to anchoring self-management into daily practice. Breath counting was consistently used by participants in the heat of the moment to alleviate stress and increase calm, and was 
frequently used as a precursor to the other tools. The CRM tracking skill, also fell into this category. Once respondents noticed the physical sensations associated with their emotions, they were more likely to use the other tactical tools such as breath counting and grounding.

Finally, a sub-category of boosts to training was included as "substitute methods," when it was discovered that several participants were using their own interpretations of meditation and selfmanagement in the study, which is in line with the literature on controlling attention through flow activities (Csikszentmihalyi, 1990). For example, participants reported using a combination of activities such as riding a motorcycle, listening to music, or working out at the gym coupled with MESM skills to manage their stress.

\section{Convergence of Data}

Quantitative results suggest MESM practice was associated with increased mindful attention, and positive experiences, and decreased negative experiences in participants in the experiment group (those who received both MESM training and practiced meditation at home). In the final phase of analysis, quotes were extracted from journals and interviews that helped illuminate these quantitative results. Samples of these excerpts appear below.

Increased Mindful Attention: "I now stop and take a deep breath whenever things get crazy...(laughs) several times a day", "I noticed how I lose control of my emotions instead of reacting calmly...I don't have to do that anymore", "I suffer from anxiety...now I have something to do before bed instead of worrying about everything that happened today", "...by staying calm and focused it kept my son calm and allowed the emergency personnel to do what they needed to do and because I was calm and focused they included me in the trauma unit."

Increased Positive Experiences: "I didn't notice a change (after three weeks of practice), but my wife did, so I guess that I'll keep going", "Instead of watching TV while checking Facebook, I meditated...it's a conscious act that allows me to check in with my body and shut down my mind before I go to bed", "This was so useful that I taught my mom and sisters how to meditate."

Decreased Negative Experiences: "My supervisor was speaking condescending to me, so I took a deep breath and listened without getting upset...she seemed deflated by my behavior", "I'm so glad that you came to give this talk when you did...I needed these skills for what was going on in my life", "I finally got some sleep, my boyfriend is in Afghanistan and I hadn't slept in months. Thank you."

\section{DISCUSSION}

As hypothesized, MESM trainees scored higher on attentional control and well-being measures than the control group after a three-week intervention. However, the proof of concept is revealed in the quotes extracted from this sample of working adults, which indicate that chronic and traumatic stress are present in the workforce, and that MESM tools can be utilized to help trainees cope with stress related symptoms, as well as real-world stressors.

Organizations currently rely on shortened versions of clinical mindfulness based interventions, perhaps due to intolerance of the typical eight-week format (e.g., Aikens et al., 2014). However these truncated interventions may lack the training elements that have led to clinical success (Good et al., 2015). This pilot study is critical because it attempts to join conversants from neuroscience, and organizational and clinical research, to improve the efficacy of organizational stress management interventions.

However, we acknowledge several limitations in this pilot study. First, the study utilized quasiexperimental design and a convenience sample. Next, the outcome measures were collected via selfreport surveys rather than physiological stress measures. And follow-up measures were not collected; therefore we cannot determine the long-term effect of this short-term intervention. Additionally, this 
sample fell short of the recommended number of participants for multivariate analyses, which led to a lack of statistical power in the analysis of the comparison group. And finally, we note that the post-test measures for the training groups were administered during mid-term exams and post-tests for the control group were administered during Thanksgiving week; both of these seasonal influences may introduce a threat to valid inference for this set of data (Campbell \& Stanley, 1963).

Several trainees reported they were more likely to continue using MESM skills when others noticed a behavior change. For future MESM design we suggest that a group setting may provide better feedback and reinforcement of training and therefore a more conducive learning environment. Trainees also reported using contemplative, proto-contemplative, and flow activities (e.g. reading the Qur'an, working out, riding a motorcycle) coupled with MESM skills to reduce stress. While only four participants made such reports, these activities could be considered as a "boost" to training or as a completely different modality of stress management in subsequent MESM designs.

We close by reiterating that the outcomes of MESM are intentionally tied to person level measures rather than organizational metrics such as productivity. Organizational studies suggest that interventions geared toward organization level goals do not offer the same stress management benefits as trainings that focus on the individual (e.g., Van Daele, Hermans, Van Audenhove, \& Van den Bergh, 2012). As with clinical mindfulness based programs, the emphasis of this intervention is human well-being. The founder of MBSR, Jon Kabat-Zinn, describes mindfulness as a basic human right, to be in touch with what is going on in our minds and emotions, and to live life as if it really mattered (Kabat-Zinn, 1990). The importance of this work cannot be understated, as the benefits of a healthy individual extend beyond the organization into society, and ultimately shape the world in which we live.

\section{ACKNOWLEDGEMENTS}

The authors acknowledge Jeremy P. Hunter and Elaine Miller-Karas for creating practical programs to help those dealing with chronic and traumatic stress and for sharing this wisdom around the world. We also acknowledge Tenzin Gyatso, the $14^{\text {th }}$ Dalai Lama for the directive to integrate modern education with mental and emotional health education, and B. Alan Wallace for extending the challenge to bring person level well-being into focus in the organizational domain. Finally, our heartfelt thanks go to Andrew Lac for his guidance in conducting statistical analyses, and Rebecca J. Reichard, Michelle C. Bligh, and Jorge A. Barraza for their assistance in preparing the manuscript.

\section{REFERENCES}

Adams, M. (2009). Change your questions change your life: 10 powerful tools for life and work(2nd ed.). San Francisco, CA: Berrett-Koehler.

Aikens, K. A., Astin, J., Pelletier, K. R., Levanovich, K., Baase, C. M., Park, Y. Y., \& Bodnar, C. M. (2014). Mindfulness goes to work: Impact of an online workplace intervention. Journal of Occupational and Environmental Medicine, 56, 721-731.

American Psychological Association. (2014). Annual Stress in America report. Retrieved from http://www.apa.org/news/press/releases/stress/2014/stress-report.pdf

Arnsten, A. F. T. (1998). Neuroscience enhanced: The biology of being frazzled. Science, 280, 17111712. http://dx.doi.org/10.1126/science.280.5370.1711

Bandura, A. (1969). Principles of behavior modification. New York, NY: Holt, Rinehart \& Winston.

Bandura, A. (1971). Social Learning Theory. Stanford, CA: General Learning Corporation.

Brown, K. W., \& Ryan, R. M. (2003). The benefits of being present: Mindfulness and its role in psychological well-being. Journal of Personality and Social Psychology, 84, 822-848. http://dx.doi.org/10.1037/0022-3514.84.4.822

Campbell, D. \& Stanley, J. (1963). Experimental and quasi-experimental designs for research. Chicago, IL: Rand-McNally. 
Cannon, W. B., (1915). Bodily changes in pain, hunger, fear and rage. New York, NY: D. Appleton \& Company.

Chambers, R., Lo, B. C. Y., \& Allen, N. B. (2008). The impact of intensive mindfulness training on attentional control, cognitive style, and affect. Cognitive Therapy and Research, 32, 303-322.

Chiesa, A., \& Serretti, A. (2009). Mindfulness-Based Stress Reduction for stress management in healthy people: A review and meta-analysis. The Journal of Alternative and Complementary Medicine, 15, 593-600. http://dx.doi.org/10.1089/acm.2008.0495

Citron, S., \& Miller-Karas, E. (2013). Community Resiliency Training innovation report. Retrieved from http:/traumaresourceinstitute.com/wp-content/uploads/2014/12/Attachment-1-CRM-EvaluationReport-Includes-Holistic-Group-09.05.13-FINAL-VERSION-51.pdf

Cohen, J. (1988). Statistical power analysis for the behavioral sciences (2nd ed.). Hillsdale, NJ: Erlbaum.

Creswell, J. W. (2013). Steps in conducting a scholarly mixed methods study. Discipline-Based Education Research Speaker Series, Paper 48. Retrieved from http://digitalcommons.unl.edu/dberspeakers/48

Csikszentmihalyi, M. (1990). Flow: The psychology of optimal experience (1st ed.). New York, NY: HarperCollins.

Diener, E., Wirtz, D., Tov, W., Kim-Prieto, C., Choi, D. W., Oishi, S., Biswas-Diener, R. (2009). New well-being measures: Short scales to assess flourishing and positive and negative feelings. Social Indicators Research, 97, 143-156.

Downe-Wamboldt, B. (1992). Content analysis: Method, applications, and issues. Health Care for Women International, 13, 313-321.

Dweck, C. S. (2008). Mindset: The new psychology of success. New York, NY: Ballantine Books. Fredrickson, B. L. (2009). Positivity (1 st ed.). New York, NY: Random House.

Gardiner, B. (2012). Business skills and Buddhist mindfulness. Wall Street Journal online, retrieved from www.wsj.com.

Gelles, D. (2012). Mindful work: How meditation is changing business from the inside out. New York, NY: Houghton Mifflin Harcourt.

Glaser, B. G., \& Strauss, A. L. (1967). The discovery of grounded theory: Strategies for qualitative research. Chicago, IL: Aldine.

Goh, J., Pfeffer, J., \& Zenios, S. A. (2015). The relationship between workplace stressors and mortality and health costs in the United States. Management Science. Advance online publication. http://dx.doi.org/10.1287/mnsc.2014.2115

Goleman, D. (1996). Emotional intelligence (10th anniversary ed.). New York, NY: Bantam Dell.

Good, D. J., Lyddy, C. J., Glomb, T. M., Bono, J. E., Brown, K. W., Duffy, M. K., Baer, R. A., Brewer, J. A., \& Lazar, S. W. (2015). Contemplating mindfulness at work: An integrative review. Journal of Management, 42, 114-142. http://dx.doi.org/10.1177/0149206315617003

Greene, J. C., Caracelli, V. J., \& Graham, W. F. (1989). Toward a conceptual framework for mixedmethod evaluation designs. Educational Evaluation and Policy Analysis, 11, 255-274. http://dx.doi.org/10.2307/1163620

Hasenkamp, W., Wilson-Mendenhall, C. D., Duncan, E., \& Barsalou, L. W. (2012). Mind wandering and attention during focused meditation: A fine-grained temporal analysis of fluctuating cognitive states. Neuroimage, 59, 750-760. doi:10.1016/j.neuroimage.2011.07.008

Hölzel, B. K., Carmody, J., Vangel, M., Congleton, C., Yerramsetti, S. M., Gard, T., \& Lazar, S. W. (2011). Mindfulness practice leads to increase in regional brain gray matter density. Psychiatry Research: Neuroimaging, 191, 36-43. http://dx.doi.org/10.1016/j.pscychresns.2010.08.006

Hsieh, H. F., \& Shannon, S. E. (2005). Three approaches to qualitative content analysis. Qualitative Health Research, 15, 1277-1288. http://dx.doi.org/10.1177/1049732305276687

Hunter, J. P. (Producer). (2013). Building Attention [Audio file]. Retrieved From http://jeremyhunter.net/resources/. 
Hunter, J. P., \& Drucker, P. F. (2009). Knowledge worker productivity and the practice of selfmanagement. The Drucker difference: what the world's greatest management thinker means to today's business leaders. New York, NY: McGraw-Hill Professional.

Kabat-Zinn, J. (1990). Full catastrophe living: Using the wisdom of your body and mind to face stress, pain, and illness (15th anniversary ed.). New York, NY: Bantam Dell.

Kabat-Zinn, J., Lipworth, L., \& Burney, R. (1985). The clinical use of mindfulness meditation for the self-regulation of chronic pain. Journal of Behavioral Medicine, 8, 163-190. http://dx.doi.org/10.1007/BF00845519

Korte, S. M., Koolhaas, J. M., Wingfield, J. C., \& McEwen, B. S. (2005). The Darwinian concept of stress: Benefits of allostasis and costs of allostatic load and the trade-offs in health and disease. Neuroscience \& Biobehavioral Reviews, 29, 3-38.

Langer, E. J., Heffernan, D., \& Kiester, M. (1988). Reducing burnout in an institutional setting: An experimental investigation. Unpublished manuscript, Harvard University, Cambridge, MA.

LeDoux, J. E. (1994). The amygdala: Contributions to fear and stress. Seminars in Neuroscience, 6, 231237. http://dx.doi.org/10.1006/smns.1994.1030

Leitch, M. L., \& Miller-Karas, E. (2010). It takes a community. Psychotherapy Networker, NovemberDecember. Retrieved from https://www.thresholdglobalworks.com/portfolio-items/it-takes-acommunity/

Leitch, M. L., Vanslyke, J., \& Allen, M. (2009). Somatic experiencing treatment with social service workers following Hurricanes Katrina and Rita. National Association of Social Workers, 54, 9-18. http://dx.doi.org/10.1093/sw/54.1.9

Lindkvist, K. (1981). Approaches to textual analysis. In K. E. Rosengren (Ed.), Advances in content analysis (pp. 23-41). Beverly Hills, CA: Sage.

MacKillop, J., \& Anderson, E. J. (2007). Further psychometric validation of the mindful attention awareness scale (MAAS). Journal of Psychopathology and Behavioral Assessment, 29, 289-293.

Matousek, R. H., Dobkin, P. L., \& Preussner, J. (2010). Cortisol as a marker for improvement in mindfulness-based stress reduction. Complementary Therapies in Clinical Practice, 16, 13-19.

Miles, J., \& Shevlin, M. (2001). Applying regression and correlation: A guide for students and researchers. London, England: Sage.

Miller-Karas, E. M. (2015). Building resilience to trauma: The Trauma and Community Resiliency Models. New York, NY: Routledge.

Moore, M., Brown, D., Money, N., \& Bates, M. (2011). Mind-body skills for regulating the autonomic nervous system [White paper]. Retrieved from Defense Centers of Excellence:

http://www.dcoe.mil/content/Navigation/Documents/Mind-

Body $\% 20$ Skills\%20for\%20Regulating\%20the\%20Autonomic\%20Nervous\%20System.pdf

Octlund, U., Kidd, L., Wengstrom, Y., \& Rowa-Dewar, N. (2011). Combining qualitative and quantitative research within mixed method research designs: A methodological review. International Journal of Nursing Studies, 48, 369-383. http://dx.doi.org/10.1016/j.ijnurstu.2010.10.005

Onwuegbuzie, A. J. (2003). Effect sizes in qualitative research: A prolegomenon. Quality \& Quantity: International Journal of Methodology, 37, 393-409.

Ospina, M. B., Bond, K., Karkhaneh, M., Tjosvold, L., Vandermeer, B., Liang, Y., Bialy, L., Hooton, N., Buscemi, N., Dryden, D. M., Klassen, T. P. (2007). Meditation practices for health: state of the research. Evidence Report/Technology Assessment. PubMed, 155: 1-263.

Porges, S. W. (2004). Neuroception: a subconscious system for detecting threats and safety. Zero to Three, 24, 19-24.

Sapolsky, R. M. (2004). Why zebras don't get ulcers (3 ed.). New York, NY: Holt Paperbacks.

Segal, Z. V., Teasdale, J. D., \& Williams, M. G. (2004). Mindfulness-based cognitive therapy: theoretical rationale and empirical status. In S. C. Hayes, V. M. Follette, \& M. M. Linehan (Eds.), In Mindfulness and acceptance: expanding the cognitive-behavioral tradition (pp. 45-65). New York, NY: Guilford Press. 
Siegel, D. J. (2010). The mindful therapist: A clinician's guide to mindsight and neural integration. New York, NY: W.W. Norton.

Siegel, D. J. (2011). Mindsight: The new science of personal transformation. New York, NY: Bantam Paperbacks.

Siegrist, J. (2001). A theory of occupational stress. In J. Dunham, (Ed.), Stress in the workplace: Past, present, and future, (pp. 52-66). Philadelphia, PA: Whurr Publishers.

Trauma Resource Institute. (2014). iChill (2.0) [Mobile application software]. Retrieved from https://play.google.com/store/apps/details?id=com.tritrc.ichill\&hl=en

Van Daele, T., Hermans, D., Van Audenhove, C., \& Van den Bergh, O. (2012). Stress reduction through psychoeducation: a meta-analytic review. Health Education \& Behavior, 39. 474-485.

Weick, K. E., \& Putnam, T. (2006). Organizing for mindfulness: Eastern wisdom and Western knowledge. Journal of Management Inquiry, 15, 275-287. http://dx.doi.org/10.1177/1056492606291202

Weick, K. E., Sutcliffe, K. M., \& Obstfeld, D. (1999). Organizing for high reliability: Processes of collective mindfulness. In B. Staw \& R. Sutton (Eds.), Research in Organizational Behavior, 21, 81-123. Greenwich, CT: JAI

Wilson, T. D. (2002). Strangers to ourselves: Discovering the adaptive unconscious. Cambridge, Mass: The Belknap Press of Harvard University Press.

World Health Organization (2013). Comprehensive mental health action plan 2013-2020. Retrieved from http://www.who.int/mental_health/action_plan_2013/en/ 


\section{Appendix A \\ Instructions for Weekly Experience Journals}

\section{Experience Journal}

Week 1

Stressful Moments: This week you will keep a journal of stressful moments in your day including: a) causes of the stress b) the sensations you felt in your body (be specific! "My throat clenches" or "My stomach tightens") c) what emotions are associated with this stress d) how did you behave e) what was the result of your behavior $f$ ) was this the most effective response? If you don't have many incidents this week, then draw from your memory of past stressful events. Write up a one to two paragraph summary at the end of the week describing your experiences.

\section{Week 2}

Calming Moments: In contrast to last week, you will keep a journal of peaceful and calming moments in your day. Please log the following: what was the cause of the calm? What did it feel like in your body? (Be specific! "My shoulders relaxed" or "My feet tingled"). What emotions are associated with this calm? How did you behave? What was the result of your behavior? If you find you don't have many incidents, then draw from your memory of past peaceful moments. Write up a one to two paragraph summary at the end of the week describing your experiences.

\section{Week 3}

Self-Management: Putting together your experiences over the past 2 weeks, journal about how your practice has influenced your daily life. Please include: a) examples of changes in your own behaviors (how you relate to yourself), b) changes in your relationships (how you relate to others), and c) changes in your job/school life (how you relate to your work). It's perfectly okay if the changes are small. Write up a one-page summary at the end of the week describing your experiences. 


\section{Appendix B \\ Interview Protocol}

Trainees were invited to share their experiences after week three. Two banks of questions were utilized: one to get a feel for the trainees' overall experiences with the process, and a second to get a feel for their interpretation of "meditation" and "self-management".

The purpose of this study is to determine how the self-management training that you received earlier this month has impacted your life, whether negatively, positively, or not at all.

For the purpose of this study:

Self-management is defined as taking responsibility for one's own behavior and well-being, and using tools such as focused breathing, body scanning, and grounding to accomplish these goals.

Meditation is defined as an exercise to quiet the mind with the goal of increasing focused concentration.

Bank 1: Regarding your self-management practice, tell me about

a) one specific example of when you used (or wish you had used) your self-management tools during the past week

b) now that you have the experience from this example, what will you do with this information going forward into next week?

Bank 2: Regarding your self-management practice, tell me about

a) what "meditation" means to you in your own words (e.g. I sit quietly and clear my mind)

b) what "self-management" means to you in your own words (e.g. I choose not to blow-up when someone upsets me)

c) an example of when you utilized a) meditation in your daily life during the past week

d) an example of when you utilized b) self-management in your daily life during the past week 


\section{Appendix C \\ Interview Analysis Codebook}

Barriers to Training

Lack of commitment

Lack of motivation

Confusion

Distraction

Failure to use tools

Boosts to Training

Identifying major stressors

Interoceptive awareness

Active choice to use tools

Connecting practice to results

Substitute versions of

meditation

Substitute versions of

self-management
Cited reasons for failure to implement self-management practice

Participant couldn't find time to work training into their lives

Participant "felt lazy" or uninspired to practice

Participant didn't use the tools, but noticed they could now "calm down and focus"

Distraction prevented use of tools- they realized they had tools "after the fact"

Participant ruminated rather than using the tools

Reasons for progress in self-management practice

Participant identified major stressors and prepared for

entering into those situations by engaging the tools

Participant noticed changes in sensations in the body and used these signals to

engage their tools

Once participants were triggered, they chose to try out

the tools of the training

Participants able to connect their practice to results were more apt to say

they might continue practice

Substitute methods used to calm the mind

Substitute interpretations of self-management were used 


\section{Appendix D \\ Document Analysis Codebook}

\begin{tabular}{|c|c|}
\hline Barriers to Training & Cited reasons for failure to implement self-management practice \\
\hline Self-criticism & $\begin{array}{l}\text { Participant judged their performance, which } \\
\text { distracted them from the practice and challenged } \\
\text { goal attainment }\end{array}$ \\
\hline Discomfort & $\begin{array}{l}\text { Participant found the practice uncomfortable, which } \\
\text { impacted their desire to engage the tools }\end{array}$ \\
\hline Skepticism & $\begin{array}{l}\text { Participant's pre-conceived biases influenced } \\
\text { their ability to see change over time }\end{array}$ \\
\hline Misapplication & $\begin{array}{l}\text { Participants were using other techniques or cherry-picking } \\
\text { portions of the training rather than using all the tools }\end{array}$ \\
\hline Boosts to Training & Cited reasons for progress in self-management practice \\
\hline Identifying major stressors & $\begin{array}{l}\text { Participant identified major stressors and prepared for } \\
\text { entering into those situations by engaging the tools }\end{array}$ \\
\hline Interoceptive awareness & $\begin{array}{l}\text { Participant noticed changes in sensations in the body and used } \\
\text { these signals to engage their tools }\end{array}$ \\
\hline Active choice to use tools & $\begin{array}{l}\text { Once participants were triggered, they chose to try out } \\
\text { the tools of the training }\end{array}$ \\
\hline Substitute techniques & $\begin{array}{l}\text { Participants used their own definition of "meditation" like } \\
\text { riding a motorcycle, or listening to loud music }\end{array}$ \\
\hline Connecting practice to results & $\begin{array}{l}\text { Participants able to connect their practice to results were more apt to } \\
\text { incorporate training in following weeks }\end{array}$ \\
\hline
\end{tabular}

